\title{
GESTÃO DO CONHECIMENTO NO BRASIL: VISÃO DA ACADEMIA i ii
}

\author{
KNOWLEDGE MANAGEMENT IN BRAZIL: A VIEW FROM THE ACADEMY
}

Recebido em 12.07.2012 Aprovado em 12.03.2013

Avaliado pelo sistema double blind review

DOI: http://dx.doi.org/10.12712/rpca.v7i1.187

\section{Andrea Cherman}

acherman@iag.puc-rio.br

Departamento de Administração de Empresas [IAG] - Pontifícia Universidade Católica do Rio de Janeiro [PUC-Rio] - Rio de Janeiro - RJ, Brasil.

\section{Sandra Regina da Rocha-Pinto}

sanpin@iag.puc-rio.br

Departamento de Administração de Empresas [IAG] - Pontifícia Universidade Católica do Rio de Janeiro [PUC-Rio] - Rio de Janeiro - RJ, Brasil.

\begin{abstract}
Resumo
A adoção da gestão do conhecimento [GC] por acadêmicos e profissionais foi analisada por Scarbrough e Swan (2001; 2003) por meio do modelo de modas e modismos de gestão empresarial (ABRAHAMSON, 1991; 1996). Este artigo objetiva replicar o trabalho desses autores no contexto brasileiro, mediante a revisão de artigos publicados em periódicos nacionais e no Encontro da Associação Nacional de Pós-Graduação e Pesquisa em Administração [EnANPAD] de 2001 a 2012. Foram apresentados, respectivamente, 69 e 28 artigos em GC nestes meios. Os resultados sugerem que a GC no Brasil não se originou das modas dos sistemas integrados de informação; o fenômeno parece também estar ligado à área de estudos organizacionais e estratégia. Encontramse presentes as características do modelo de moda de gestão relacionadas à difusão dos conceitos de GC entre os grupos de interesse e suas tentativas de apropriação e legitimação do discurso por cada grupo. Os vários discursos facilitam e amplificam a difusão do movimento. Entretanto, tornam a GC um campo complexo, ambíguo, fragmentado e de difícil gerenciamento, justamente em função da interação complexa entre as áreas da administração.
\end{abstract}

Palavras-chave: Gestão do conhecimento. Modas e modismos da gestão empresarial. Teoria da Difusão da Inovação.

\begin{abstract}
The adoption of knowledge management [KM] for academics and professionals was analyzed by Scarbrough and Swan $(2001 ; 2003)$ using the model of fashions and fads in business management (ABRAHAMSON, 1991; 1996). This article aims to replicate the work of these authors and analyze the Brazilian context by reviewing the articles published at national journals and at Annual Meeting of the Brazilian Academy of Management [EnANPAD]. Between 2001 and 2012, 69 and 28 articles were presented through these media, respectively. The results suggest that $\mathrm{KM}$, in Brazil, did not originate from fashions of integrated information systems, the phenomenon seems also linked to the area of strategy and organizational studies. Some characteristics of the fashion managerial model are present, related to the spread of KM among interest groups and their attempts to appropriate the discourse and to legitimate it by each group. The various speeches facilitate and amplify the spread of the movement, however make the KM field complex, ambiguous, fragmented and difficult to manage, precisely because of the complex interaction among the business administration areas.
\end{abstract}

Keywords: Knowledge management. Managerial fads and fashions model. Diffusion of Innovation Theory. 


\section{Introdução}

A gestão do conhecimento [GC] tem recebido interesse crescente na área de gestão empresarial (SCARBROUGH \& SWAN (2003). Das quatro linhas de estudo relacionadas à aprendizagem e ao conhecimento organizacionais, a gestão do conhecimento foi a última a surgir, em fins dos anos 90, por intermédio do trabalho seminal de Davenport e Prusak (1998). Porém, Nonaka (1994) e Nonaka e Takeuchi (1997) tiveram um papel fundamental ao popularizar o movimento do conhecimento organizacional, antecipando e introduzindo, indiretamente, os conceitos relacionados à gestão do conhecimento em seus trabalhos (EASTERBY-SMITH e LYLES, 2003).

A rápida emergência e adoção da gestão do conhecimento por acadêmicos e profissionais nas organizações, no contexto internacional, foram explicadas por Scarbrough e Swan $(2001 ; 2003)$ por meio da difusão do discurso pelo modelo de modas e modismos de gestão empresarial ${ }^{\text {iii }}$ (ABRAHAMSON, 1991; 1996), que toma como base a teoria da difusão da inovação (ROGERS, 2003). Moda e modismo são termos empregados para descrever a difusão de tecnologias administrativas que procuram racionalizar ou otimizar o desempenho organizacional; porém, essas modas e modismos são caracterizadas pela imitação como principal fator de impulso à sua adoção (ABRAHAMSON, 1991).

Abrahamson (1991) utiliza-se do trabalho de Rogers (2003), com vistas a analisar a difusão e a rejeição de determinadas tecnologias de gestão, assim como estabelecer um modelo que caracterize os fatores determinantes das modas e dos modismos da gestão empresarial. Em seus trabalhos, baseados em análise das publicações de artigos acadêmicos, Abrahamson abordou a difusão e adoção dos movimentos de círculos de qualidade (CQ) e de venda de ações aos funcionários (ABRAHAMSON, 1996; ABRAHAMSON e FAIRCHILD, 1999), assim como qualidade total (TQM), reengenharia de processos $\left(\mathrm{BPR}^{\mathrm{iv}}\right.$ ) e enriquecimento de cargo (ABRAHAMSON e FAIRCHILD, 1999). Outros autores também exploraram os movimentos de CQ e TQM (PONZI e KOENING, 2002), como também a gestão do conhecimento (PONZI e KOENING, 2002, SCARBROUGH e SWAN, 2001; 2003). Nesse último caso, a análise também incorporou revistas executivas, publicações de consultorias, associações de classe e profissionais, entre outros.

Quando se observam as tecnologias de gestão empresarial emergentes desde a década de 80 dentre as quais se podem adicionar às já mencionadas, a produção just-in-time (JIT), além do kaizen e kanban, os movimentos de excelência em serviços, os movimentos de certificação para qualidade (ISO), a institucionalização da responsabilidade social corporativa e socioambiental (RSC, RSA), a adoção das terceirizações e parceirizações, a configuração de negócios em forma matricial, em unidades de negócios e, mais atualmente, em redes, para citar algumas tecnologias de gestão -, torna-se relevante investigar o quanto a adoção de uma inovação trata-se realmente de uma necessidade no complexo contexto competitivo pós-industrial ou apenas uma imitação da moda de gestão empresarial.

A relevância mencionada acima diz respeito tanto ao contexto prático das organizações e seus administradores, que adotam as práticas de gestão, quanto para a academia, que funciona como produtora e difusora dessas mesmas práticas. Desse modo, este trabalho objetiva replicar e comparar o trabalho de Scarbrough e Swan (2003), acerca da difusão e adoção da gestão do conhecimento, ao contexto brasileiro. Para tanto, foi realizada a revisão dos: 1) artigos publicados em doze periódicos nacionais, classificados pelo ranking Qualis-CAPES, e 2) trabalhos apresentados no principal congresso nacional da área de administração, o EnANPAD, desde o ano de 1998, quando o primeiro artigo sobre gestão do conhecimento apareceu no congresso, até 2012. Para este estudo, foram utilizados, ao final, os artigos dos últimos doze anos, desde o ano de 2001.

Nas próximas seções serão apresentados: a) uma revisão conceitual dos quatro campos de estudo 
relacionados à aprendizagem e ao conhecimento organizacionais, com vistas a contextualizar a evolução desses movimentos na linha do tempo; b) os conceitos da teoria da difusão da inovação e o modelo de modas e modismos de gestão empresarial. $\mathrm{O}$ percurso metodológico, especialmente a coleta dos artigos analisados, encontra-se na quarta seção, seguida pela análise dos resultados encontrados. Por fim, são apresentadas as conclusões e implicações para a área acadêmica, responsável em grande parte pela produção e difusão das tecnologias gerenciais, e para o contexto prático dos profissionais e organizações, adotantes das inovações ou das modas de gestão.

\section{Gestão do conhecimento e os movimentos de aprendizagem e conhecimento organizacionais}

Easterby-Smith e Lyles (2003) classificaram os quatro campos de estudo, interligados e complementares, que se desenvolveram no campo da aprendizagem e do conhecimento no contexto das organizações. Os autores partiram de duas dimensões: 1) o aspecto tratado por esse campo de estudo, ou seja, processo / aprendizagem ou conteúdo / conhecimento; e 2) a forma de abordagem do aspecto, isto é, vertente teórica ou intervenção prática na organização. O primeiro campo de estudo, que despontou no início dos anos 60 e se disseminou a partir da década de 70 , foi a aprendizagem organizacional, a qual abarca os processos de aprendizagem por meio dos quais se dá o conhecimento nas organizações.

Em seguida, no fim dos anos 80, emergiu o conceito de organização de aprendizagem, entendida como a instituição capaz de possuir características e arranjos estruturais e culturais, viabilizadores dos processos de aprendizagem. Esse campo possui uma vertente eminentemente prática e foi disseminado por intermédio de trabalhos de consultores (como, por exemplo, SENGE, 1998) e executivos (como DE GEUS, 1988).

O conhecimento organizacional teve seus conceitos clássicos estabelecidos muito antes, com os trabalhos de Hayek (1945) e Penrose (2006; publicado pela primeira vez em 1959), vindos da economia, e de Dewey $(1948,1998)$ e Polanyi (1966), originários da filosofia. Porém, apenas no fim dos anos 80 e principalmente nos anos 90, o tema ganhou popularidade com os trabalhos de Nonaka (1994) e Nonaka e Takeuchi (1997). Na classificação dos autores, o conhecimento organizacional é o entendimento sobre a natureza do conhecimento que é contido nas organizações; abarcando os aspectos relativos a conteúdo, tipificação, transferência, aquisição, capacidade de absorção, utilização e criação. Representa, enfim, uma teoria acerca desse conhecimento.

Por fim, a gestão do conhecimento foi o último campo de estudo a surgir ao final da década de 90 com o trabalho de Davenport e Prusak (1998). Esse tipo de gestão pode ser compreendido como o modo de intervenção prática e intencional por parte da organização para gerar conteúdo de conhecimento organizacional (EASTERBY-SMITH e LYLES, 2003). A gestão do conhecimento ganhou legitimidade e intensa disseminação com a apropriação dos trabalhos de Nonaka para este campo de estudo e pela alavancagem proporcionada pelos outros campos de estudo ao longo do tempo (EASTERBY-SMITH e LYLES, 2003).

Embora exista uma fronteira conceitual entre os quatro campos apresentados acima, que ficou mais claramente estabelecida na revisão de Easterby-Smith e Lyles (2003), há de se reconhecer, junto com os próprios autores, que a dinâmica, a complementaridade e a emergência dos campos, em consonância com o desenvolvimento dos conceitos interligados, não são suficientes para estabelecer delimitações tão distintas quanto se poderia ou se gostaria de supor. Em conseqüência, uma revisão da produção em qualquer uma dessas áreas de estudo apresenta uma complexidade adicional: a necessidade de reclassificar os artigos em função dos conceitos abordados e autores utilizados.

\section{Difusão e adoção de inovação e modas da gestão empresarial}




\section{A Teoria da Difusão da Inovação e as modas e modismos da gestão empresarial}

Inovação é uma ideia, uma prática ou um objeto percebido como novo por um indivíduo ou outra unidade de adoção, como organizações ou instituições. Rogers (2003) define difusão como o processo por meio do qual uma inovação é comunicada através de certos canais durante algum período de tempo entre os membros de um sistema social. A difusão, portanto, é um tipo especial de comunicação, relativa com a disseminação de mensagens, as quais são percebidas como novas ideias.

Neste sentido, as diversas práticas e os movimentos de gestão empresarial emergentes nas últimas décadas são inovações que apresentam novas tecnologias administrativas para incremento do desempenho organizacional. A taxa de adoção de uma inovação é determinada pela forma como as características dessa inovação são percebidas pelos membros do sistema social. O sistema social, por sua vez, é o conjunto inter-relacionado de indivíduos, grupos informais, associações, organizações, instituições, ou outros sub-sistemas, que se engajam conjuntamente na solução de problemas para atingir uma meta comum, e que estabelecem as fronteiras dentro das quais a inovação é difundida (ROGERS, 2003).

Além disso, a comunicação é um importante fator, responsável por criar conhecimento e reduzir a incerteza acerca da adoção da inovação. Quanto mais intensa e mais interpessoal for a comunicação, mais efetiva será a formação e a mudança de atitudes em relação a uma nova idéia. A maior parte dos indivíduos avalia uma inovação não com base em pesquisa científica, mas por intermédio de avaliações subjetivas de indivíduos de referência (líderes de opinião, organizações de primeira linha, grupos de referência) e pares próximos que a adotaram. Dessa forma, o sistema social tem papel relevante de influência no processo de adoção ou rejeição de uma inovação (ROGERS, 2003).

O tempo é outro elemento a ser considerado. A adoção não ocorre simultaneamente por todos os indivíduos; ocorre em grupos de adotantes, os quais possuem características distintas. Após a adoção pelos inovadores, os adotantes iniciais (ou líderes de opinião) são fundamentais para a ampla e bem sucedida difusão da inovação, tanto pela maioria inicial como pela maioria tardia, e por fim, pelos retardatários. Esses grupos de adotantes configuram-se em uma curva de adoção da inovação, de distribuição normal em forma de sino, em uma linha de tempo. A curva do número de adotantes em uma difusão bem sucedida, por sua vez, assume a forma de S (ROGERS, 2003).

Considerando esses elementos, Abrahamson (1991) propôs um modelo para analisar os movimentos de inovação de tecnologia administrativa adotados pelas organizações, avaliando quais características configuram a adoção da inovação como uma mera moda ou modismo de gestão empresarial. A moda de gestão empresarial é definida como "uma crença coletiva, relativamente transitória, disseminada por agentes que definem as modas gerenciais, as quais a técnica de gestão conduz ao progresso gerencial racional" (ABRAHAMSOM, 1996, P.257). Alguns autores advogam que as modas e modismos facilitam a difusão de novas tecnologias administrativas, enquanto outros argumentam que eles são símbolos que sinalizam inovação por parte das empresas adotantes, mas que pouco contribuem para a melhoria de desempenho organizacional (ABRAHAMSON, 1991).

Segundo Abrahamson (1991), a adoção ou rejeição de inovações de tecnologias administrativas podem ocorrer em quatro perspectivas explicativas. Elas são resultado de uma matriz que considera, de um lado, a dimensão de foco na imitação por parte das empresas - se o processo de imitação impele ou não a difusão ou rejeição; e de outro lado, a dimensão de influência externa da decisão de adoção ou rejeição - se organizações, dentro ou fora de um determinado grupo, têm a capacidade de determinar a adoção ou rejeição da inovação administrativa neste grupo. Em outras palavras, o quanto o grupo de empresas é vulnerável às influências externas de outras organizações, setores ou 
indústrias.

Desse modo, se uma organização determina a difusão ou rejeição dentro de um grupo e o processo de imitação não impulsiona a difusão ou rejeição, então se tem a perspectiva de escolha eficiente; a organização adota um processo decisório baseado em metas próprias, de modo independente das demais. No caso de uma organização externa determinar a difusão ou a rejeição, ou seja, uma situação de poderio empresarial, mas o processo de imitação não impelir a difusão ou rejeição, apresenta-se a perspectiva de seleção forçada. Assim, o exemplo de organizações fortes ou poderosas, geralmente benchmarking de seus setores, pode pressionar outras empresas a adotar inovações ineficientes para elas, ou rejeitar inovações eficientes (ABRAHAMSON, 1991). A esse respeito, Davenport e Prusak (1998), Nonaka e Takeuchi (1997), entre outros autores, apresentaram em seus trabalhos inúmeros casos de gestão do conhecimento e conhecimento organizacional aplicados a diversas corporações de primeira linha, como IBM, Honda, Merck, Boeing, Citibank, 3M, HP, Microsoft. Tais ilustrações, podem ter contribuído no processo de seleção forçada sobre outras empresas - ou mesmo, da moda e modismo de gestão, que serão vistos a seguir.

As perspectivas do modismo e da moda ocorrem na dimensão do processo de imitação, o qual, efetivamente, impele a difusão ou a rejeição da inovação. Em ambos os casos, a tomada de decisão centra-se menos na tecnologia que deve ser adota para a melhoria do desempenho organizacional e mais em torno de qual organização deve ser imitada. A perspectiva do modismo ocorre por influência de organizações dentro do grupo ao qual a empresa faz parte, enquanto a perspectiva da moda sofre influência de organizações externas ao grupo do qual a empresa participa (ABRAHAMSON, 1991).

No que diz respeito ao modismo, que acontece dentro do grupo ao qual a empresa pertence, há uma explicação para que esse fenômeno ocorra, conforme preconizado por Rogers (2003): a comunicação do conhecimento, as interações sociais ou interesses econômicos dentro do grupo, são processos redutores da ambigüidade acerca da adoção da inovação, além de serem os aspectos responsáveis por sua difusão ou rejeição (ABRAHAMSON, 1991). Na perspectiva da moda, empresas de consultoria, gurus em gestão empresarial, mídia de negócios, escolas de administração ou associações profissionais, por exemplo, são as organizações externas à empresa que se revestem no papel de agentes definidores das modas, promovendo determinados modelos de gestão e tecnologias administrativas que devem ser adotados ou rejeitados (ABRAHAMSON, 1991; 1996). A legitimação do discurso da moda concorre para a própria legitimação da organização ou grupo que o difunde, e vice-versa.

Abrahamson (1996) apresentou as características determinantes do conceito de moda de gestão empresarial. As modas são rápidas, com curva de adoção em forma de sino de acordo com a popularidade da tecnologia administrativa (uma distribuição normal do número de adotantes, conforme a teoria de Rogers, 2003). Além disso, necessitam passar pelo processo de definição de moda. Para tanto, envolvem os agentes definidores das modas de gestão empresarial mencionados. A adesão e a perda de interesse por parte dos profissionais por uma moda de gestão é explicada pelas ondas de interesse em tecnologias administrativas, que ocorrem quando normas de racionalidade (para o melhor desempenho) e de progresso (inovação e estado da arte) guiam os comportamentos gerenciais, exigindo novas tomadas de decisão.

Desse modo, Abrahamson (1996) procura investigar em suas pesquisas (CQ, TQM, BPR, entre outros): o quanto as modas caminham em ondas (ABRAHAMSON, 1996) e possuem um efeito propulsor $^{\vee}$ (bandwagon effect) para a moda seguinte, dentro da mesma área de ação (ABRAHAMSON e ROSENKOPF, 1993); em que medida esses movimentos legitimam acadêmicos, grupos profissionais, consultores e escolas de negócios, fazendo proliferar as modas empresariais (ABRAHAMSON, 1996; SCARBROUGH e SWAN, 2003); ou, o quanto a adoção de 
uma inovação trata-se realmente de uma necessidade competitiva para melhor performance organizacional.

\section{Os Estudos de Scarbrough e Swan (2001; 2003) acerca da Difusão e Adoção da Gestão do Conhecimento}

Com base nos conceitos mencionados nos tópicos anteriores, Scarbrough e Swan (2001; 2003) analisaram os movimentos de organização de aprendizagem e gestão do conhecimento. Esses dois campos de estudo têm em comum a vertente prática, possuindo modelos para aplicação e intervenção nas organizações. Foram amplamente disseminados por trabalhos publicados por consultores e gurus de gestão (como SENGE, 1989; e DAVENPORT e PRUSAK, 1998) em organizações de destaque, com poder de influência sobre as demais.

Em sua revisão da literatura, cujo período compreende dez anos, de 1990 a 2000, Scarbrough e Swan (2003) analisaram, inicialmente, a quantidade de publicações nestas áreas. A Figura 1 espelha a quantidade de trabalhos no período em análise (retirado de SCARBROUGH e SWAN, 2001). A gestão do conhecimento emerge com força a partir de 1998. Os autores ressaltam o efeito propulsor que os anos anteriores de publicações no campo de organizações de aprendizagem geraram sobre a gestão do conhecimento. Após a emergência da gestão do conhecimento, o movimento de organizações de aprendizagem não ganhou um novo impulso; não apresentou uma nova onda de publicações. Pode-se concluir, então, que um movimento acabou substituindo o outro.

Figura 1: Curva de referências encontradas em Gestão do Conhecimento (barra preta) e Organizações de Aprendizagem (barra branca).

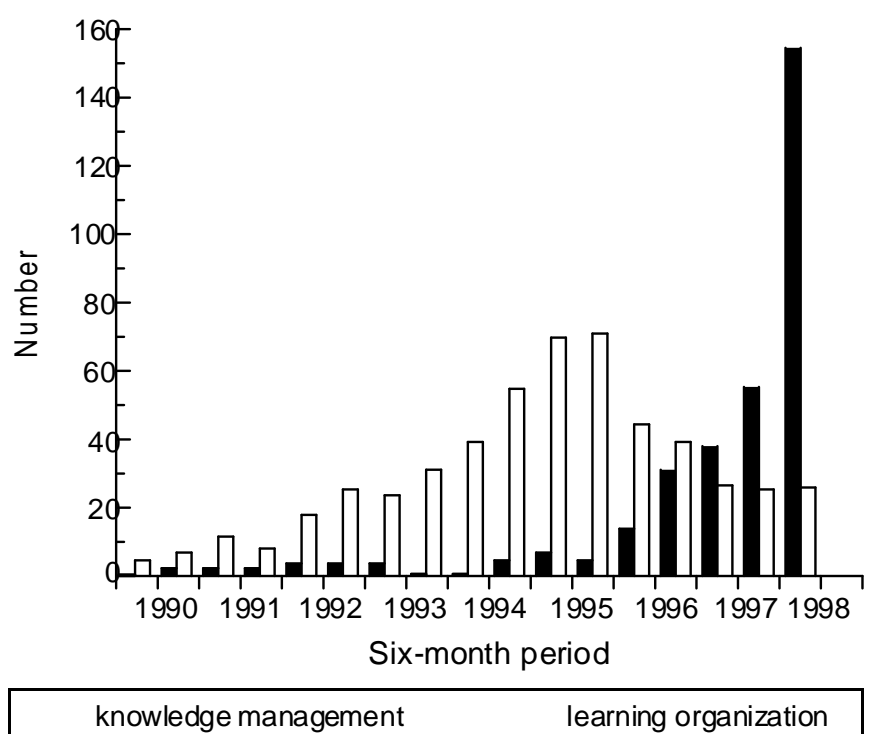

Fonte: Scarbrough e Swan, 2001, p. 6.

Ainda na análise quantitativa, aproximadamente $70 \%$ dos artigos em 1998 surgiram na literatura de tecnologia da informação e sistemas de informação (TI/SI). O conteúdo dessa literatura era eminentemente prático, e não teórico; diversos artigos eram publicados em periódicos orientados para profissionais, conduzidos por consultores, gurus e empresas de consultoria (KPMG, IBM Consulting, McKinsey, Ernst Young, entre outras). Os autores advogam que o discurso de gestão do conhecimento foi usado como um meio de reempacotar os produtos de TI/SI sob um novo rótulo. No período de 1993 a 1999, 50\% dos artigos de GC apareceram em periódicos de TI/SI. Ainda em 1998, 19\% dos artigos de GC apareceram na área temática de gestão estratégica, seguido por 5\% 
que foram publicados na área de recursos humanos (SCARBROUGH e SWAN, 2001).

Quanto aos temas abordados, três tópicos se destacam. O primeiro, e mais presente nos artigos publicados, diz respeito ao papel crítico da gestão do conhecimento para a melhoria do desempenho organizacional. $\mathrm{O}$ pressuposto central aborda as pressões crescentes das empresas sob a complexidade do ambiente e da globalização, e, portanto, a necessidade de desenvolver as capacidades de gestão do conhecimento. O segundo tema trata da gestão do conhecimento como um recurso estratégico para obtenção de vantagem competitiva. O terceiro tópico destaca o processamento e armazenamento de conhecimento, onde o foco se centra nas ferramentas de TI, banco de dados de conhecimento, intranets, ferramentas de suporte à decisão (SCARBROUGH e SWAN, 2003). Os autores encontraram correspondência entre os resultados encontrados na pesquisa e as características do modelo de moda de gestão empresarial, apontados por Abrahamson (1991; 1996). A curva de publicações de gestão do conhecimento tem a forma de sino, obtida em apenas seis anos de publicações, de 1997 a 2000 (SCARBROUGH e SWAN, 2003). O rápido crescimento a partir de 1998 é uma característica clara de efeito propulsor gerado pelos anos anteriores de publicações em organizações de aprendizagem, sendo que uma onda (de GC) substituiu a outra (de OA).

O segundo aspecto se refere ao discurso associado à moda, onde uma moda atual precisa se diferenciar da anterior para legitimar-se. Nesse caso, os autores encontraram que a gestão do conhecimento tem termos associados à tecnologia de informação, ao capital intelectual e aos sistemas de informação. Organização de aprendizagem está relacionada ao treinamento, ao desenvolvimento organizacional e aos recursos humanos. Por fim, o conteúdo do discurso, no modelo de moda, deve combinar ambiguidade com simplicidade, conforme apresentado por Rogers (2003). Ambiguidade traduz-se por uma conceituação vaga o suficiente para possibilitar várias interpretações e facilitar a ampla difusão e adoção, enquanto a simplicidade também favorece a comunicação e rápida difusão. Sob esse aspecto, o discurso de gestão do conhecimento encontrado é basicamente de casos de melhores práticas, que funcionam como exemplo e referência.

Scarbrough e Swan (2003) observam o contexto e os agentes que definem as modas de gestão, conforme preconiza Abrahamson (1996). Na revisão feita, os autores evidenciam a importância dos consultores, gurus da gestão empresarial e acadêmicos na disseminação desse discurso. Além disso, a fragmentação e contradição aparecem com a importância dos grupos profissionais na difusão do discurso. Nesse caso, os profissionais de TI, profissionais de RH, profissionais em posições estratégicas nas organizações procuram, cada qual legitimar a gestão do conhecimento sob sua perspectiva profissional, de auto-interesse, dando origem à colonização e apropriação do discurso. Os autores concluem que a gestão do conhecimento permitiu diferentes discursos de gestão para os diversos grupos. Tal constatação demonstra como a interação se tornou complexa, com diferentes contextos, discursos e práticas, que se refletem no próprio gerenciamento do conhecimento.

\section{Metodologia}

A partir de uma revisão de literatura da produção acadêmica brasileira dos artigos relativos à Gestão do Conhecimento - apresentados no Encontro da Associação Nacional de Pós-Graduação e Pesquisa em Administração EnANPAD e nos periódicos brasileiros classificados no Qualis-CAPES entre A2 e B2, no período de doze anos, de 2001 a 2012 -, este artigo busca investigar a difusão e a adoção desse movimento de gestão do conhecimento, com base na teoria de difusão de inovação, de Rogers (2003), e no modelo das modas da gestão empresarial, de Abrahamson (1991, 1996). Para tanto, replica o estudo e compara os resultados com os achados de Scarbrough e Swan (2001; 2003). Do mesmo modo que no estudo original desses autores, o movimento da gestão do conhecimento foi avaliado sob o prisma da adoção da inovação na área de gestão empresarial, sujeito ao discurso 
legitimador das modas (ABRAHAMSON, 1991).

Assim, visto que o dado de análise é composto por artigos publicados em periódicos brasileiros e listados nos anais do principal congresso acadêmico da área de administração, este estudo é do tipo bibliográfico (VERGARA, 2006). Além da revisão dos artigos publicados em periódicos, a opção pela revisão dos artigos apresentados em congresso deveu-se a três fatores. Primeiro, em função da maior rapidez do surgimento e da inserção do tema em um congresso anual, quando comparado com as publicações em periódicos, que possuem prazos maiores de revisão-aceitação e flexibilidade editorial variável para incorporar um novo tema. Segundo, tendo o congresso um cunho acadêmico, julgou-se que esse fórum teria um público mais atento aos movimentos de gestão internacionais e, por fim, o local seria propício para apresentação da adoção de inovações aplicadas no contexto empírico brasileiro.

O levantamento inicial foi realizado considerando os artigos indexados pelas palavras-chave "aprendizagem" e "conhecimento", com objetivo de trazer todos os artigos dos quatro campos de estudo de referência: aprendizagem organizacional, organização de aprendizagem, conhecimento organizacional e gestão do conhecimento. Dada as limitações dos mecanismos de busca, procedeuse, também, à leitura dos índices de trabalhos apresentados por congresso e dos resumos dos artigos. Esse procedimento foi necessário em função de: a) ampla diversidade de temas explorados na área de conhecimento e aprendizagem organizacionais; b) confusão na delimitação conceitual dos artigos que exigiu sua reclassificação; c) delimitação de foco desta própria pesquisa de revisão no campo da Gestão do Conhecimento.

O ano de 1998 foi o marco do primeiro artigo sobre gestão do conhecimento no EnANPAD. Em doze edições do referido congresso, foram coletados 178 artigos. Todos os artigos foram examinados por seu conteúdo e reclassificados conforme o modelo de Easterby-Smith e Lyles (2003), dando origem ao quantitativo expresso na Tabela 1. Desse modo, esta pesquisa trabalhou com 69 artigos no campo de estudo de Gestão do Conhecimento.

Tabela 1: Produção Acadêmica Nacional no EnANPAD

\begin{tabular}{cccccc}
\hline Ano & $\begin{array}{c}\text { Gestão do } \\
\text { Conhecimento }\end{array}$ & $\begin{array}{c}\text { Aprendizagem } \\
\text { Organizacional }\end{array}$ & $\begin{array}{c}\text { Conhecimento } \\
\text { Organizacional }\end{array}$ & $\begin{array}{c}\text { Organização de } \\
\text { Aprendizagem }\end{array}$ & Total \\
\hline $\mathbf{2 0 0 1}$ & 3 & 4 & 2 & 0 & 1 \\
$\mathbf{2 0 0 2}$ & 4 & 3 & 0 & 0 & 8 \\
$\mathbf{2 0 0 3}$ & 5 & 4 & 0 & 0 & 9 \\
$\mathbf{2 0 0 4}$ & 5 & 3 & 2 & 0 & 10 \\
$\mathbf{2 0 0 5}$ & 6 & 3 & 4 & 0 & 13 \\
$\mathbf{2 0 0 6}$ & 7 & 8 & 6 & 0 & 21 \\
$\mathbf{2 0 0 7}$ & 10 & 7 & 2 & 0 & 19 \\
$\mathbf{2 0 0 8}$ & 9 & 6 & 3 & 0 & 18 \\
$\mathbf{2 0 0 9}$ & 6 & 5 & 7 & 0 & 18 \\
$\mathbf{2 0 1 0}$ & 7 & 11 & 6 & 0 & 24 \\
$\mathbf{2 0 1 1}$ & 4 & 6 & 4 & 0 & 14 \\
$\mathbf{2 0 1 2}$ & 3 & 7 & 6 & $\mathbf{1}$ & 16 \\
\hline Total & $\mathbf{6 9}$ & $\mathbf{6 7}$ & $\mathbf{4 1}$ & $\mathbf{1 7 8}$ \\
\hline
\end{tabular}

Fonte: Desenvolvido pelas autoras

A Tabela 2 apresenta a lista de periódicos e o número de artigos publicados nos quatro campos de aprendizagem e conhecimento organizacional. Foram revisados doze periódicos, classificados pelo Qualis-CAPES entre A2 e B2, pelo período de doze anos. Neste período, foram coletados 101 artigos, sendo 28 no campo de Gestão do Conhecimento. Por sua vez, a Tabela 3, apresenta o número de artigos publicados por ano. 
Tabela 2: Periódicos Brasileiros Pesquisados

\begin{tabular}{|c|c|c|c|c|c|}
\hline Publicação & $\begin{array}{c}\text { Gestão do } \\
\text { Conhecimento } \\
\end{array}$ & $\begin{array}{l}\text { Aprendizagem } \\
\text { Organizacional }\end{array}$ & $\begin{array}{l}\text { Conhecimento } \\
\text { Organizacional }\end{array}$ & $\begin{array}{c}\text { Organização de } \\
\text { Aprendizagem }\end{array}$ & Total \\
\hline $\begin{array}{l}\text { Brazilian Administration Review } \\
\text { BAR }\end{array}$ & 1 & 1 & 2 & & 5 \\
\hline $\begin{array}{l}\text { Revista de Administração } \\
\text { Pública RAP }\end{array}$ & 2 & 5 & 2 & 1 & 10 \\
\hline $\begin{array}{l}\text { Revista de Adm. Contemporânea } \\
\text { RAC }\end{array}$ & 3 & 12 & 3 & & 18 \\
\hline $\begin{array}{l}\text { Revista de Adm. de Empresas } \\
\text { RAE }\end{array}$ & 1 & 3 & & & 4 \\
\hline RAE Eletrônica & 3 & 4 & 2 & & 9 \\
\hline Cadernos EBAPE & 2 & 5 & 1 & & 8 \\
\hline $\begin{array}{l}\text { Revista de Adm. Mackenzie } \\
\text { RAM }\end{array}$ & 3 & 13 & 2 & & 18 \\
\hline Brazilian Business Review BBR & & 1 & & & 1 \\
\hline Revista de Administração USP & 3 & 2 & & 2 & 7 \\
\hline $\begin{array}{l}\text { Revista Eletrônica de Adm. } \\
\text { REAd }\end{array}$ & 6 & 4 & 2 & & 12 \\
\hline $\begin{array}{l}\text { Revista de Administração FEA- } \\
\text { USP }\end{array}$ & 4 & 3 & 1 & & 8 \\
\hline $\begin{array}{l}\text { Base Revista de Adm. } \\
\text { UNISINOS }\end{array}$ & & & 1 & & 1 \\
\hline Total & 28 & 54 & 16 & 3 & 101 \\
\hline
\end{tabular}

Fonte: Desenvolvido pelas autoras

Tabela 3: Produção Acadêmica Nacional em Periódicos por Ano de Publicação

\begin{tabular}{rcccrr}
\hline Ano & $\begin{array}{c}\text { Gestão do } \\
\text { Conhecimento }\end{array}$ & $\begin{array}{c}\text { Aprendizagem } \\
\text { Organizacional }\end{array}$ & $\begin{array}{c}\text { Conhecimento } \\
\text { Organizacional }\end{array}$ & $\begin{array}{c}\text { Organização de } \\
\text { Aprendizagem }\end{array}$ & Total \\
\hline $\mathbf{2 0 0 1}$ & 1 & 4 & & 1 & $\mathbf{6}$ \\
$\mathbf{2 0 0 2}$ & 1 & 3 & 1 & & $\mathbf{4}$ \\
$\mathbf{2 0 0 3}$ & 4 & 2 & & 1 & $\mathbf{7}$ \\
$\mathbf{2 0 0 4}$ & 3 & 7 & 3 & 1 & $\mathbf{1 1}$ \\
$\mathbf{2 0 0 5}$ & 2 & 1 & 2 & & $\mathbf{6}$ \\
$\mathbf{2 0 0 6}$ & & 4 & 1 & & $\mathbf{1 1}$ \\
$\mathbf{2 0 0 7}$ & 5 & 4 & 1 & $\mathbf{8}$ \\
$\mathbf{2 0 0 8}$ & 5 & 2 & 2 & $\mathbf{1 0}$ \\
$\mathbf{2 0 0 9}$ & 4 & 4 & 3 & 1 \\
$\mathbf{2 0 1 0}$ & 1 & 7 & 1 & $\mathbf{1 1}$ \\
$\mathbf{2 0 1 1}$ & 1 & 8 & 2 & $\mathbf{1 0}$ \\
$\mathbf{2 0 1 2}$ & 1 & 8 & $\mathbf{1 6}$ & $\mathbf{1 1}$ \\
\hline Total & $\mathbf{2 8}$ & $\mathbf{5 4}$ & & $\mathbf{1 0 1}$ \\
\hline
\end{tabular}

Fonte: Desenvolvido pelas autoras

\section{Resultados}

Difusão e Adoção da Inovação e o modelo de modas de gestão sob a ótica de artigos de gestão do conhecimento

Cabe destacar alguns pontos iniciais na análise quantitativa dos artigos coletados. Observou-se que, enquanto os movimentos relacionados à aprendizagem e ao conhecimento surgiram em momentos distintos e sequenciados na literatura internacional, no Brasil, eles emergiram concomitantemente na academia. Em 1998, ano em que a pesquisa de Scarbrough e Swan (2001; 2003) aponta como expressivo o crescimento do movimento de GC, aparece o primeiro artigo no EnANPAD. 
Se a aprendizagem organizacional estabeleceu um efeito propulsor para o movimento de GC na literatura internacional, tal fenômeno não ocorreu no Brasil. $\mathrm{O}$ movimento da organização de aprendizagem nunca se firmou no congresso nacional, muito menos como uma moda. Talvez, a explicação esteja no fato de que, ao chegar ao Brasil, o movimento de organização de aprendizagem já estivesse em declínio no exterior. Além disso, conforme analisaram Scarbrough e Swan (2003), ele não teve uma segunda onda; o movimento de GC substituiu OA.

Quanto ao gráfico com curva de adoção em forma de sino, de acordo com a popularidade da gestão do conhecimento (ABRAHAMSON, 1996; ROGERS, 2003), os doze anos de revisão apontam para uma tendência a distribuição normal do número de artigos apresentados no EnANPAD (ver Figura 2). O pequeno número de artigos publicados em periódicos no tema de GC ( 28 artigos) não permite fazer uma inferência sobre o comportamento da distribuição. Pode-se constatar um declínio do número de artigos apresentados nos dois últimos anos de congresso e declínio mais claro na publicação em revistas científicas. A curva da adoção de GC apresentada por Scarbrough e Swan (2001; 2003), já tinha uma conformação de sino definida em seis anos de publicações em periódicos internacionais: o movimento foi adotado rapidamente, outra característica do modelo de moda de gestão. No contexto brasileiro, em dez anos de produção acadêmica, a adoção foi lenta e ainda não se pode declarar o declínio definitivo do movimento, pelo menos na participação do tema no referido congresso.

Observa-se ainda que, no caso dos artigos apresentados no EnANPAD, o crescimento da adoção nos primeiros anos foi praticamente regular. Não houve um salto na adoção do tema em trabalhos acadêmicos do congresso, como foi visto na publicação em periódicos internacionais. $\mathrm{O}$ ano de maior crescimento foi 2007, ano em que a divisão acadêmica de Administração da Informação (ADI) abriu o tema de Gestão da Informação e Conhecimento no congresso. Embora em 2010 tenha sido separado o tema de Gestão do Conhecimento da Gestão da Informação em seções distintas, o número de trabalhos apresentados de GC cresceu timidamente, o que sinaliza estabilidade e posterior declínio. No próximo tópico, 5.2., serão analisadas as áreas de apresentação dos trabalhos de GC. Quanto à publicação nos periódicos pesquisados, a produção foi irregular, e, diferentemente do congresso, o movimento de aprendizagem organizacional ocupou maior espaço e relevância.

Figura 2: Distribuição do número de artigos apresentados relativos ao movimento de Gestão do Conhecimento.

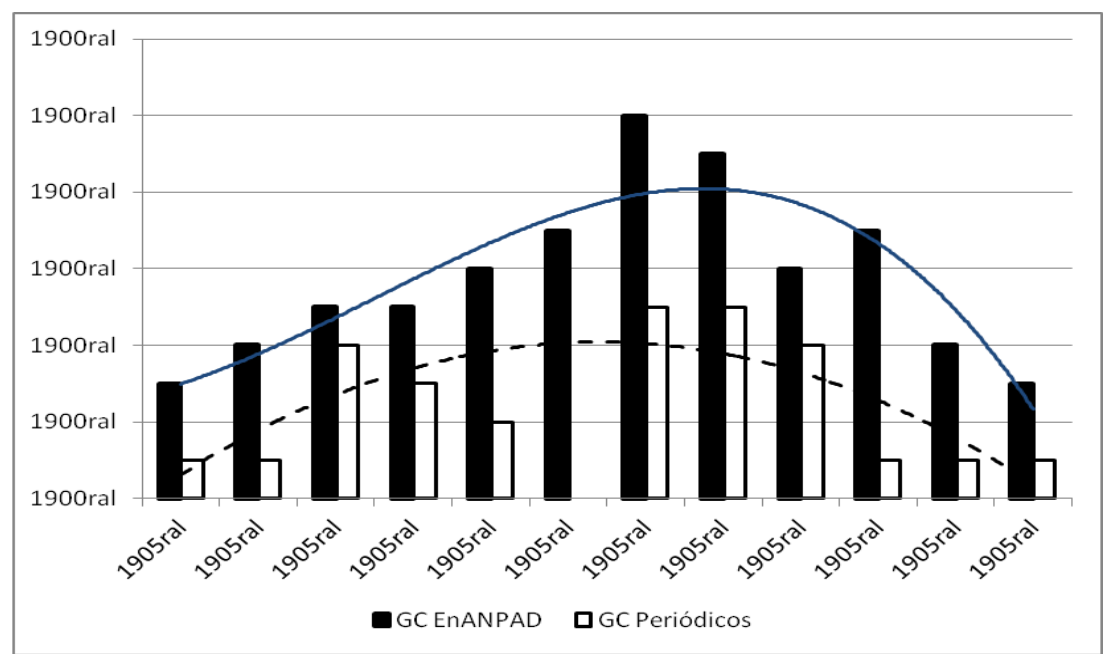

Fonte: Desenvolvido pelas autoras

A Figura 3 apresenta a curva $S$ de difusão e adoção da inovação (ROGERS, 2003), dada pelo número de trabalhos apresentados, adotantes do movimento de GC. A forma do $\mathrm{S}$ é bastante 
alongada, quase imperceptível, em função do longo tempo de acompanhamento e da lenta adoção do movimento de GC pela academia, juntamente com o limitado número de trabalhos apresentados, tanto no congresso quanto em periódicos.

\section{Figura 3: Curva da Difusão e Adoção da Inovação (ROGERS, 2003) aplicada ao movimento de Gestão do Conhecimento.}

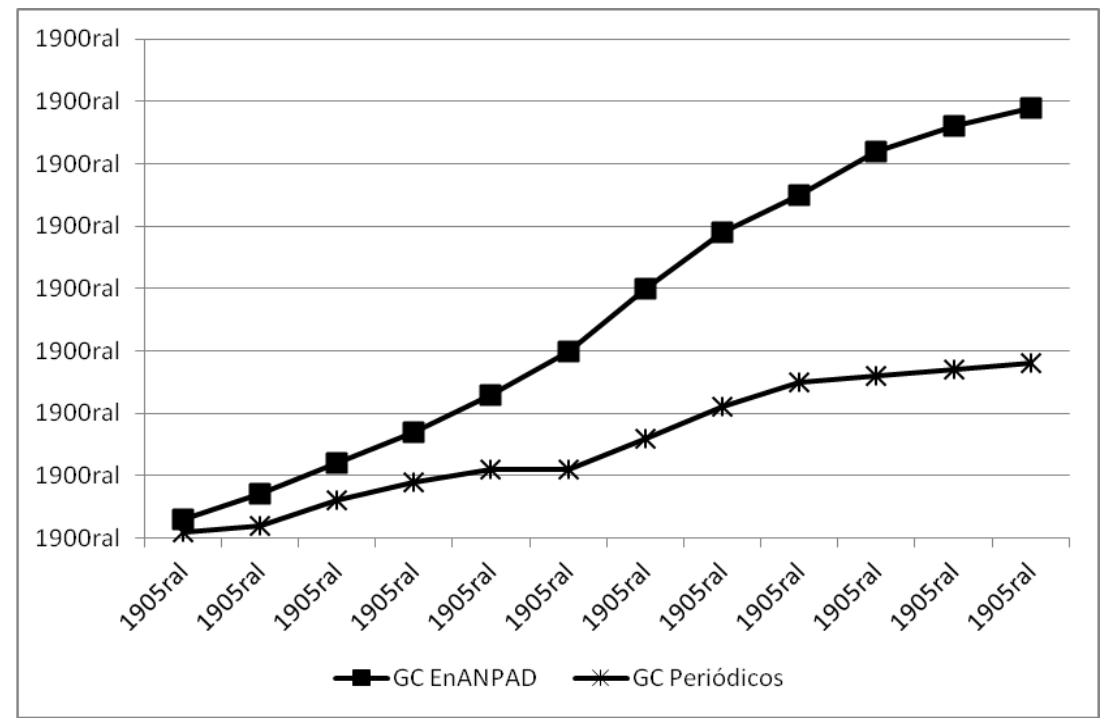

Fonte: Desenvolvido pelas autoras

\section{O Discurso da gestão do conhecimento}

Com relação ao Congresso do EnANPAD, da mesma forma que no artigo de Scarbrough e Swan (2001; 2003), a área da administração/divisão acadêmica onde foi apresentada a maioria dos artigos pesquisados sobre gestão do conhecimento foi a divisão de Administração da Informação, comportando 55\% de todos os artigos de GC. Soma-se a ela, a divisão de Gestão da Ciência e Tecnologia, com mais $13 \%$ das publicações. À primeira vista, esses números parecem confirmar-se que GC é um discurso bastante afiliado à TI/SI, conforme os achados de Scarbrough e Swan (2003). Entretanto, a análise de conteúdo dos artigos irá refutar essa interpretação, como será visto mais adiante.

A segunda divisão onde se apresentaram trabalhos em gestão do conhecimento foi a área de Estudos Organizacionais, com $17 \%$ dos artigos. Ainda houve 11\% dos trabalhos apresentados na divisão de Estratégia Organizacional, dois trabalhos em Gestão de Pessoas e Relações de Trabalho e um Caso Brasileiro em Administração. Foi possível perceber a pluralidade de abordagens do discurso, a fragmentação do contexto e a colonização do discurso por diferentes áreas da administração, fato também identificado por Scarbrough e Swan (2003).

Outro aspecto que chama a atenção diz respeito aos três últimos anos, onde, dos quatorze trabalhos de GC, apenas metade foram apresentados na área de administração da informação. Todos os demais artigos foram apresentados nas divisões de estudos organizacionais e gestão de pessoas.

Em termos de temas tratados pelos artigos de gestão do conhecimento, foram identificadas quatro linhas de abordagem principais, com bastante divergência em relação aos achados de Scarbrough e Swan (2003). O primeiro tema que emerge é a gestão de conhecimento como um importante recurso estratégico, responsável por trazer ou possibilitar novas competências para a vantagem competitiva sustentável das organizações. 32\% dos artigos versavam sobre estudos nesta linha, assim como a maioria fazia alguma menção acerca da relevância da gestão do conhecimento como 
um importante recurso estratégico.

Um achado desta pesquisa foi a identificação de que o segundo tema abordado por artigos nacionais, apresentados em congresso, dizia respeito à relação entre gestão do conhecimento e fatores organizacionais. Essa linha de abordagem, correspondente a $27 \%$ dos trabalhos, tratou de questões relativas à liderança, cultura, comunicação, motivação, autonomia no trabalho, e ao impacto das estruturas organizacionais. Também foram abordados esses aspectos relacionados com implantação de modelos de gestão do conhecimento. Nota-se uma preocupação com as condições organizacionais necessárias para a efetiva gestão do conhecimento, sem as quais GC não se torna uma realidade prática nas empresas. No artigo de Scarbrough e Swan (2003) esse enfoque sequer emerge, fato que sugere uma forte apropriação do discurso de GC pela área de estudos organizacionais no Brasil.

Desempenho organizacional, o tema mais presente nos estudos internacionais, segundo Scarbrough e Swan (2003), foi apenas o terceiro tema apresentado na revisão nacional. Nessa linha, foram abordadas propostas de indicadores e modelos de mensuração dos ativos de conhecimento, e estudos de medição de efetividade da relação entre as práticas e ferramentas de GC e a performance organizacional.

Outro achado importante diz respeito ao fato de que, apesar de $55 \%$ dos artigos terem sido apresentados na divisão acadêmica de Administração da Informação, apenas $14 \%$ de todos os trabalhos abordaram temas relacionados à TI/SI, tais como processamento e armazenamento de informações, e ferramentas de GC, ou seja, portais, intranets, gestão eletrônica de documentos (GED), business intelligence (BI), knowledge database, entre outros assuntos. Desse modo, embora à primeira vista o discurso de GC pareça afiliado à TI/SI, na realidade, por intermédio da avaliação de conteúdo dos artigos nacionais e suas linhas de abordagem, descobriu-se que o discurso de GC se aproxima das áreas de estratégia organizacional e estudos organizacionais, diferindo, expressivamente, da abordagem internacional.

Já em relação aos artigos publicados em periódicos, foi encontrado um equilíbrio entre as abordagens desenvolvidas. Os três temas de GC - como recurso e competência estratégica, como medida de desempenho organizacional e como ferramenta e modelo de TI/SI - apareceram na mesma intensidade nas revistas; todos com $27 \%$ dos artigos publicados. As três áreas se apropriaram igualmente do discurso de GC.

Foi interessante também perceber que, nos periódicos, a linha relacionada à relação entre gestão do conhecimento e fatores organizacionais aparece em apenas $15 \%$ dos artigos publicados. Se a área de estudos organizacionais apresentou grande destaque, reivindicando o discurso de GC nos congressos EnANPAD, ela não obteve o mesmo sucesso com artigos publicados em periódicos. Não é possível analisar se tal fato se deve às linhas editoriais dos periódicos.

\section{Gestão do conhecimento enquanto moda de gestão empresarial}

Essa análise destaca as várias características que concorrem para determinar se o movimento da gestão do conhecimento no Brasil assume a configuração de uma moda de gestão empresarial através dos trabalhos publicados no EnANPAD e nas publicações em periódicos.

A curva de adoção em forma de sino para os artigos do EnANPAD (Figura 2), já discutida anteriormente, apresenta uma tendência ao declínio da moda. No caso das publicações em periódicos, o declínio do tema nas publicações é mais visível ainda. Segundo Abrahamson (1996), as modas de gestão empresarial são crenças coletivas transitórias, caminham em ondas e são rapidamente substituídas por outro movimento de gestão. No Brasil, o movimento de GC 
apresentou uma difusão e uma adoção bastante lentas na academia, em comparação com o estudo de Scarbrough e Swan (2001; 2003).

A curva da adoção de GC tampouco apresenta um grande pico de adoção, fato esse que caracterizaria uma moda (ABRAHAMSON, 1996), ou seja, a entrada da maioria de adotantes naquela inovação (ROGERS, 2003). No modelo de modas, o pico também seria o resultado do efeito propulsor das ondas das modas que antecederam ao movimento (ABRAHAMSON, 1996; SCARBROUGH \& SWAN, 2003). Conforme pode ser observado nas Tabelas 1 e 3, no Brasil, os movimentos de organização de aprendizagem, conhecimento organizacional e aprendizagem organizacional surgiram quase ao mesmo tempo na academia, e assim, pode-se concluir que esses movimentos não geraram efeito propulsor uns nos outros.

Uma segunda característica do modelo de moda diz respeito à construção do discurso. No estudo internacional de Scarbrough e Swan (2003), a GC tinha claramente um discurso afiliado à área de TI/SI, fato que trouxe uma argumentação entre os autores de novo rótulo para vender as ferramentas de TI/SI. Pela análise das áreas de apresentação dos trabalhos e dos conteúdos dos artigos nacionais, a gestão do conhecimento não se tornou um tema relacionado a uma única área. De fato, ele foi igualmente apropriado pelas áreas de estratégia de empresas, relacionado aos recursos e competências organizacionais, e de estudos organizacionais, ligado às condições estruturais, culturais e gerenciais para sua implementação. Na verdade, por influência dos trabalhos de Nonaka e Takeuchi (1997), os artigos nacionais se aproximam mais da perspectiva do conhecimento organizacional do que propriamente gestão do conhecimento (na linha de Davenport, Prusak, Fahey, Teece, entre outros autores que muito publicaram em 1998). Pode-se inferir, também, que, se GC foi uma nova onda de uma moda de gestão, esse movimento se encontra no âmbito da estratégia e gestão, e não somente na esfera de TI/SI - pelo menos pela perspectiva da academia como um agente difusor de modas de gestão.

A terceira característica relaciona-se com a ambiguidade e a simplicidade do discurso. A conceituação de gestão do conhecimento utilizada nos artigos nacionais tem origem na literatura internacional, e traz a ambiguidade apontada por Scarbrough e Swan (2003). A revisão dos trabalhos expõe tanto a falta de unicidade quanto a de uma definição clara do que é gestão do conhecimento, assim como uma grande confusão conceitual com relação ao campo de estudo de conhecimento organizacional, e mesmo de aprendizagem organizacional. Conforme é definido em um dos artigos analisados, "gestão do conhecimento é um conceito guarda-chuva", o que permitiria muitas temáticas embaixo dele, confirmando a ambiguidade. Deve-se ressaltar, entretanto, que os artigos publicados nos periódicos, especialmente os mais recentes, já apresentam uma melhor delimitação do campo de estudo, possivelmente fruto da maturidade que o tema vem ganhando com o tempo.

Entretanto, a simplicidade apontada pelo estudo internacional necessita de uma consideração adicional. Ela é representada por casos de melhores práticas e por modelos difundidos por gurus e consultores, traduzindo-se em aplicabilidade da moda. Dada a variedade de pesquisas empíricas encontradas, a maioria em estudos de caso e algumas poucas pesquisas quantitativas, constata-se que os casos favorecem a ampla aplicabilidade de GC em diversas empresas de diferentes setores e contextos. Entretanto, deve-se levar em conta que esta revisão se restringe, apenas, a trabalhos acadêmicos apresentados no congresso do EnANPAD e em doze publicações científicas editadas no Brasil. Assim, este estudo não captura toda a dimensão do estudo de Scarbrough e Swan (2001; 2003). Desse modo, este estudo aborda a perspectiva de apenas um agente difusor do sistema social (ROGERS, 2003): os acadêmicos (e, em menor, escala seu papel nas escolas de negócios). Não podemos inferir sobre esse critério de simplicidade em outros agentes difusores, como as revistas de negócios ou consultorias. 
A última característica é dada pela colonização do discurso pelas diversas áreas da administração. A profusão de casos em empresas de diversos setores, apresentados em áreas de acadêmicas distintas, reforça o discurso polifônico mencionado por Scarbrough e Swan (2003), que facilita a difusão do movimento de GC entre estes agentes. Há uma busca pela autolegitimação das linhas de abordagem por cada grupo de acadêmicos das diferentes áreas da administração: estratégia organizacional, estudos organizacionais, TI/SI, gestão de recursos humanos. Confirma-se a tentativa de apropriação da gestão do conhecimento nessas abordagens, por meio de temáticas próprias.

\section{Conclusões e implicações}

Em síntese, entende-se que não se pode caracterizar a gestão do conhecimento, no Brasil, enquanto uma moda de gestão empresarial, do mesmo modo como apresentado no estudo internacional. A GC, no país, parece ter adquirido um contorno mais crítico e avaliativo das questões que impactam ou se relacionam ao movimento, e menos a conotação prescritiva e positivista, baseada em modelos, ferramentas e iniciativas, que marcaram a literatura internacional.

Os resultados, nesta pesquisa, demonstram que a gestão do conhecimento não se originou das modas dos sistemas integrados de informação - ou, pelo menos, não unicamente delas. E, se a GC originou-se de algum movimento (ou moda), essa influência parece estar mais ligada à área de estratégia (pela corrente da Visão Baseada em Recursos e Visão Baseada em Conhecimento) e aos estudos organizacionais (por meio das competências individuais e organizacionais, e das novas estruturas em rede e modelos de gestão descentralizada). Os doze anos de produção acadêmica neste campo parece estar se esgotando, com a queda na produção e publicação no tema, porém não sugere ter dado lugar a outro movimento, o que caracterizaria uma moda.

Ainda assim, algumas características componentes do modelo de moda de gestão estão presentes, e são os aspectos relacionados à difusão dos conceitos de GC entre os grupos de interesse e as tentativas desses grupos na apropriação e legitimação do discurso. A polifonia com diferentes discursos e práticas, pouco interligados, se reflete na realidade prática. Por um lado, os vários discursos facilitam e amplificam a difusão do movimento. Por outro, eles tornam a gestão do conhecimento um campo complexo, ambíguo, fragmentado e de difícil gerenciamento, justamente em função da interação complexa entre as áreas da administração.

Para profissionais e organizações, adotantes de tecnologias de administração, considera-se que o último aspecto tem grande relevância. Na experiência prática corporativa, a dificuldade de implantação de gestão do conhecimento tem alimentado os estudos empíricos acadêmicos: desalinhamento das práticas; multiplicação de iniciativas; conflitos de gerenciamento entre as áreas de planejamento estratégico, recursos humanos, tecnologia da informação e alta gestão; falta de entendimento dos membros organizacionais acerca dos projetos de GC; ou mesmo dúvidas a respeito de como mensurar os seus resultados; entre outras questões. Se a gestão do conhecimento é uma inovação tecnológica de administração necessária ao desempenho organizacional, e não uma moda ou modismo a ser imitado, cabe à academia, como agente difusor, encontrar e propor um discurso integrativo.

As limitações desta pesquisa dizem respeito ao universo de publicações analisadas, menos abrangente que o estudo original de Scarbrough e Swan (2003). Esse fato reduz a perspectiva de análise da apropriação do discurso pelas áreas da administração. Também exclui da análise a possível difusão entre outros agentes, como, por exemplo, consultorias e revistas de negócios. Sugestões para futuras pesquisas se situam no âmbito da análise de outros movimentos de gestão empresarial, nas linhas de abordagem identificadas nesse artigo, ou seja, em estratégia e estudos organizacionais. Acredita-se que pesquisas nessas áreas podem identificar as ondas de modas 
relacionadas à gestão do conhecimento, uma vez que nelas se encontra a afinidade do discurso.

\section{Referências}

ABRAHAMSON, E. Managerial Fads and Fashions: The Diffusion and Rejection of Innovations. Academy of Management Review, v. 16, n. 3, p. 586-612, 1991.

ABRAHAMSON, E. Management Fashion. Academy of Management Review, v. 21, n. 1, p. 2542851996.

ABRAHAMSON, E., FAIRCHILD, G. Management Fashion: Lifecycles, Triggers, and Collective Learning Process. Administrative Science Quarterly, v. 44, n. 4, p. 708-740, 1999.

ABRAHAMSON, E., ROSENKOPF, L. Institutional and Competitive Bandwagons: Using Mathematical Modeling as a Tool to Explore Innovation Diffusion. Academy of Management Review, v. 18, n. 3, p. 487-517, 1993.

DAVENPORT T.H., PRUSAK, L. Conhecimento Empresarial: Como as Organizações Gerenciam o seu Capital Intelectual. Rio de Janeiro: Campus, 1998.

DE GEUS, A. Planning as Learning. Harvard Business Review, v. 66, n. 2, p. 70-74, 1988.

DEWEY, J. The Essential Dewey: Pragmatism, Education, Democracy. v. 1, IN: Indiana University Press, 1998.

DEWEY, J., BENTLEY, A.F. Knowing and the Known. Disponível em www.aier.org, acesso em 10/23/2010, 1948.

EASTERBY-SMITH, M., LYLES, M.A. Introduction: Watersheds of Organizational Learning and Knowledge Management In: EASTERBY-SMITH, M. \& LYLES, M. The Blackwell Handbook of Organizational Learning and Knowledge Management. Blackwell Publishing. p. 1-15, 2003.

GIL, A.C. Como Elaborar Projetos de Pesquisa. São Paulo: Atlas, 1989.

HAYEK, F.A. The Use of Knowledge in Society. American Economic Review, v. XXXV, n. 4. 1945

PENROSE, E.T. Teoria do Crescimento da Firma. São Paulo: Ed. UNICAMP, 2006, original de 1959.

POLANYI, M. The Tacit Dimension. New York: Doubleday \& Co, 1966.

PONZI, L.J., KOENING, M. Knowledge Management: Another Management Fad? Information Research, v. 8, n. 1, 2002.

NONAKA, I. A Dynamic Theory of Organizational Knowledge Creation. Organization Science, n. 5, p. 14-37, 1994.

NONAKA, I., TAKEUCHI, H Criação de Conhecimento na Empresa: Como as Empresas Japonesas Geram a Dinâmica da Inovação. $7^{\text {a }}$ Ed., Rio de Janeiro: Editora Campus, 1997.

ROGERS, E. Diffusion of Innovations. $5^{\text {th }}$ ed., New York: Free Press, 2003.

SCARBROUGH, H., SWAN, J. Explaining the Diffusion of Knowledge Management: The Role of Fashion. British Journal of Management, v. 12, p. 3-12, 2001.

SCARBROUGH, H., SWAN, J. Discourses of Knowledge Management and the Learning Organization: Their Production and Consumption. In.: EASTERBY-SMITH, M. \& LYLES, M. The Blackwell Handbook of Organizational Learning and Knowledge Management. Blackwell Publishing. p. 495-511, 2003. 
SENGE, P. A Quinta Disciplina: Arte e Prática da Organização que Aprende. São Paulo: Ed. Best Seller, 1998.

SWAN, J., SCARBROUGH, H., PRESTON, J. Knowledge Management: The Next Fad to Forget People? British Journal of Management, v. 12, p. 668-678, 2001.

VERGARA, S.C. Projetos e Relatórios de Pesquisa em Administração. 7 ed. São Paulo: Atlas, 2006.

' Este artigo foi apresentado originalmente no XXXVII EnANPAD (2011). Agradecemos aos revisores do referido congresso, assim como aos membros da sessão na qual ele foi apresentado. As sugestões cabíveis, feitas em ambas as situações, foram incorporadas na presente versão.

ii Agradecemos especialmente à professora Ângela da Rocha, cuja orientação acerca do Modelo de Difusão da Inovação, de Rogers (2003), inspirou o presente artigo.

iii Abrahamson apresentou o conceito de Management Fads and Fashions e Management Fashions em dois trabalhos publicados na Academy of Management Review, respectivamente em $1991 \mathrm{e}$ 1996, sendo, o segundo, premiado com o Best Paper Award no congresso da AoM de mesmo ano.

iv Do ingles, Business Process Re-engineering.

v O termo em inglês Bandwagon Effect foi traduzido para o português como efeito propulsor. Esta expressão significa que uma ação realizada anteriormente impulsiona, aumenta a dimensão, da ação seguinte. 